INSIGHTS INTO REGIONAL DEVELOPMENT

ISSN 2669-0195 (online) http://jssidoi.org/IRD/

2021 Volume 3 Number 2 (June)

http://doi.org/10.9770/IRD.2021.3.2(2)
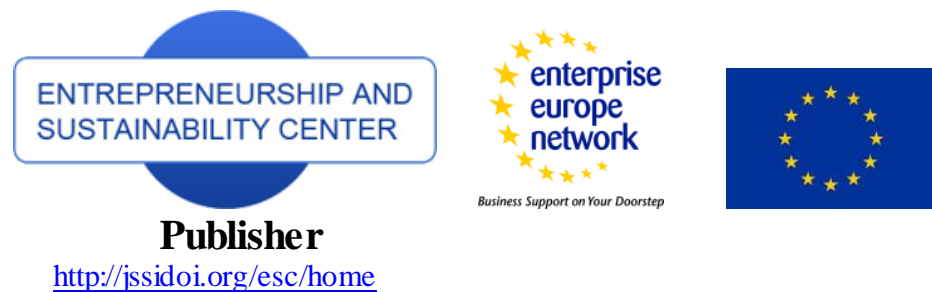

http://jssidoi.org/esc/home

\title{
TECHNO-ECONOMIC ASSESSMENT (TEA) AND LIFE CYCLE COSTING ANALYSIS (LCCA): DISCUSSING METHODOLOGICAL STEPS AND INTEGRABILITY*
}

\section{Lorenzo Giacomella}

\author{
Department of Economics and Management, University of Ferrara, Via Voltapaletto 11, 44121 Ferrara, Italy \\ E-mails: lorenzo.giacomella@student.unife.it; lorenzo.giacomella@gmail.com
}

Received 15 November 2020; accepted 10 March 2021; published 30 June 2021

\begin{abstract}
Researchers have always been concerned about investigating new methods of economic evaluation, in order to endow reliable observations and support the sustainable development of new products. In this sense, clarity and homogeneity are necessary to exploit the effectiveness of such instruments that, only in this way, can provide consistent recommendations among sectors and industries of the economy. With respect to technological innovation, two diffused methods are the techno-economic assessment (TEA) and the life-cycle costing analysis (LCCA). However, despite their diffusion and approval, these instruments still lack clear guidelines and a complete documentation of their distinctive elements. Furthermore, no discussion exists about their complementarity and integrability, despite the fact that these methods are frequently concurrently used in the analyses. With the goal of reviewing what sets one method apart from the other, this research shed some lights on the distinctive elements of TEA and LCCA, as well as providing a preliminary discussion on their (possible) methodical integration. At a first glance, present literature provides numerous cues for an analysis which aim is to improve the comprehension of the norms of application of TEA and LCCA. Though, it is necessary a reorganisation of contents which, at present time, appears heterogenous and uncoordinated. Despite some limitations and its preliminary nature, this research contributes to improve the comprehension of the methods under investigation, also introducing a new vision which sees TEA and LCCA converge in a structured model.
\end{abstract}

Keywords: techno-economic assessment; life cycle costing analysis; economic evaluation; technology readiness level; economic evaluation

Reference to this paper should be made as follows: Giacomella, L. 2021. Techno-economic assessment (TEA) and life cycle costing analysis (LCCA): discussing methodological steps and integrability. Insights into the regional development, 3(2), 176-197. http://doi.org/10.9770/IRD.2021.3.2(2)

JEL Classifications: $\mathrm{O} 1, \mathrm{O} 3$

\footnotetext{
* This research was supported by the University of Ferra ra and the TECNALIA Research and Innovation Center, Derio (Bizkaia), Spain.
} 
INSIGHTS INTO REGIONAL DEVELOPMENT

ISSN 2669-0195 (online) http://jssidoi.org/jesi/

2021 Volume 3 Number 2 (June)

http://doi.org/10.9770/IRD.2021.3.2(2)

\section{Introduction}

Minimizing the cost of projects has been a main concern of designers and constructors for many years now. Ever since technological innovation has gained a key role for a sustainable growth of the economy, more accurate and inclusive evaluation tools have been explored to guide research and development towards the market. More recently, the increasing environmental deterioration has evoked the importance for new metrics of evaluation within orthodox economic analyses. The intention is to support the advance of more comprehensive assessments, oriented to win-win outcomes - i.e. profit maximization and environmental impacts minimization. This is the case of techno-economic assessment (TEA) and life-cycle costing analysis (LCCA). However, these two evaluation methods are currently affected by the scarcity of theoretical discussion and a heterogenous practice.

In general terms, the TEA supports the identification of the most efficient pathways for technological development and assesses how a technology might be successfully deployed in a profitable and desirable way (Kuppens,2012). On the other hand, the LCCA is usually considered as a valuable method that considers the cost effectiveness of a project by embracing all phases of its life. Also, it gives a framework for estimating incremental costs of developing, producing, using and disposing of an object (Asiedu \& Gu, 1998).

Both evaluation methods are experiencing a renewed interest by academics and professional communities since not only they represent an effective mean to guide decisions during the development of a project ${ }^{\dagger}$, but also, and above all, they are open to the inclusion of environmental and social considerations. In fact, it is not surprising that most of Research and Innovation programmes (e.g. Horizon 2020) foresee specific tasks to conduct these analyses. In an optic of sustainable development, TEA and LCCA represent valuable tools to drive a more efficient utilization of resources, as well as driving and speeding up technological progress in line with nowadays' societal challenges. However, since overall established frameworks are lacking, the application of TEA and LCCA is harmed by their dependency to the specificities of single cases. In this sense, a homogenisation and development of systematic approaches may support an effective deployment of the methods, which may guarantee to take full advantage of these techniques.

With regard to TEA, most advanced guidelines are proposed within $\mathrm{CO} 2$ Utilization technologies (Zimmerman et al., 2018), chemical industry (Buchner et al., 2018) and biofuels production (Van Dael et al., 2015). Contrarily, users of LCCA can rely on few sectorial standards, as for the building (ISO15686:2017) and petroleum and natural gas industry (ISO 15663:2000) but, differently to TEA, the LCCA can count on the support of the wellrecognised and rather diffused life-cycle assessment (LCA), regulated by ISO 14040:2006. As a result, a broad spectrum of empirical approaches is applied, which ultimately not only undermines comparative analyses, but also runs the risk of generating partial and/or misleading information that may lead to the selection of sub-optimal alternatives (Ellis, 2007). Finally, even though TEA and LCCA are sometimes combined in the same analysis (Rajesh Banu et al., 2020; Zayed et al., 2020), no strict academic discussion on their integration has been revealed so far.

\subsection{Objectives and contribution}

The aim of this research is to shed some lights on the distinctive elements of TEA and LCCA, and hence exploring the potential of using the tools in an integrated fashion. So far, the lack of reliable common frameworks,

\footnotetext{
$\dagger$ Hereafter, with the term "project” we refer indistinctly to products, processes or services.
} 


\section{INSIGHTS INTO REGIONAL DEVELOPMENT}

ISSN 2669-0195 (online) http://jssidoi.org/jesi/

2021 Volume 3 Number 2 (June)

http://doi.org/10.9770/IRD.2021.3.2(2)

the self-determination of studies and the ambiguity in methodological choices, significantly reduced comparability and transparency of studies. Furthermore, the specific aspect of TEA-LCCA integration has not been addressed from a theoretical point of view. By investigating the available literature and current practices, this study provides a novel contribution to the methodological discussion on the structure of the methods, identifying and analysing the distinctive elements of these economic appraisal tools, and providing practitioners and academia with a through discussion.

Specifically, the following research questions (RQ) were addressed:

- RQ1: What are the distinctive elements of TEA and LCCA? On which basis scholars may analyse and assess these elements?

- RQ2: Are the (apparently) mutual aspects of the TEA and LCCA treated at the same way? And, to what extent the two methods can be implemented together, and what constitutes a correct integration?

As for RQ1, main distinctive elements and theoretical foundations are identified and outlined for TEA and LCCA, respectively. The reference to technological readiness levels (TRL), as an example, appeared as the most distinctive component of TEA. The LCCA, on the other hand, presents peculiarities in identifying alternatives and treating preference of time (discounting). Both methods present components of costs, profitability and uncertainty analysis.

As an answer to RQ2, what emerge is that, still treating some elements similarly, there are peculiar differences concerning, among others, the focus of the methods, their consideration of inflation, time preferences and technological performances. Finally, elaborating the information gathered through the revision of the literature, a proposal for a possible methodical combination of the tools sees the LCCA as an integrative piece of analysis for TEA. In this sense, a complete evaluation of the life-cycle cost might be implemented once the project has reached a certain degree of technological development, when a more advanced and precise consideration of the economic feasibility is required.

\section{Research methodology and background information}

The entire study was subdivided in three main phases. In a first phase, a preliminary literature review was performed to detect principal background information and current patterns of diffusion for TEA and LCCA. In this phase the following strings of search were used on Scopus database - the enquiry was executed on March 2020:

TITLE ("Techno-Economic Assessment" OR "Techno-Economic Evaluation" OR "Techno-Economic Analysis")

and,

$$
\text { TITLE ("Life Cycle Cost" OR "Life Cycle Costing"). }
$$

Overall, the research produced almost five thousand results between 1969 and 2020. Respectively, 2213 denoted techno-economic studies, while 2744 were related to LCCA, see Table 1. As for TEA some synonymous have been included in the research in order to generate a more accurate set of results, for LCCA it seemed more appropriate to include terms with lower specificity since the strong heterogeneity and poor clearness affecting the language in the field. 


\section{INSIGHTS INTO REGIONAL DEVELOPMENT}

ISSN 2669-0195 (online) http://jssidoi.org/jesi/

2021 Volume 3 Number 2 (June)

http://doi.org/10.9770/IRD.2021.3.2(2)

Table 1: Results of the preliminary research on literature

\begin{tabular}{lcc}
\hline Keywords & Results & Variation \\
\hline \hline$T E A$ & & \\
\hline Techno-Economic Assessment & 524 & - \\
Techno-Economic Assessment OR Techno-Economic Evaluation & 928 & 404 \\
Techno-Economic Assessment OR Techno-Economic Evaluation OR & 2213 & 761 \\
Techno-Economic Analysis & & \\
\hline LCCA & 2290 & - \\
\hline Life Cycle Cost & 2744 & 454 \\
Life Cycle Cost OR Life Cycle Costing & & \\
\hline
\end{tabular}

Source: Scopus database (March 2020)

Referring to abovementioned set of results, the analysis of the temporal diffusion of the studies (see Figure 1 suggests a renewed interest for TEA, against a flattening adoption of LCCA. The fact may suggest a better compliance of the first method with the necessities claimed by the technological industry, in which the production of innovation more than ever needs to deal with a higher level of complexity driven by economic aspects, but also technical, social and environmental. However, overlapping terminologies may also contribute to the polarisation of results and a poor classification of languages may hide a natural embedment of the LCCA in techno-economic analyses. It is not uncommon that peculiar techniques to LCCA are adopted without straight references to the general evaluation method. As a consequence, the correct classification of cases is potentially biased.

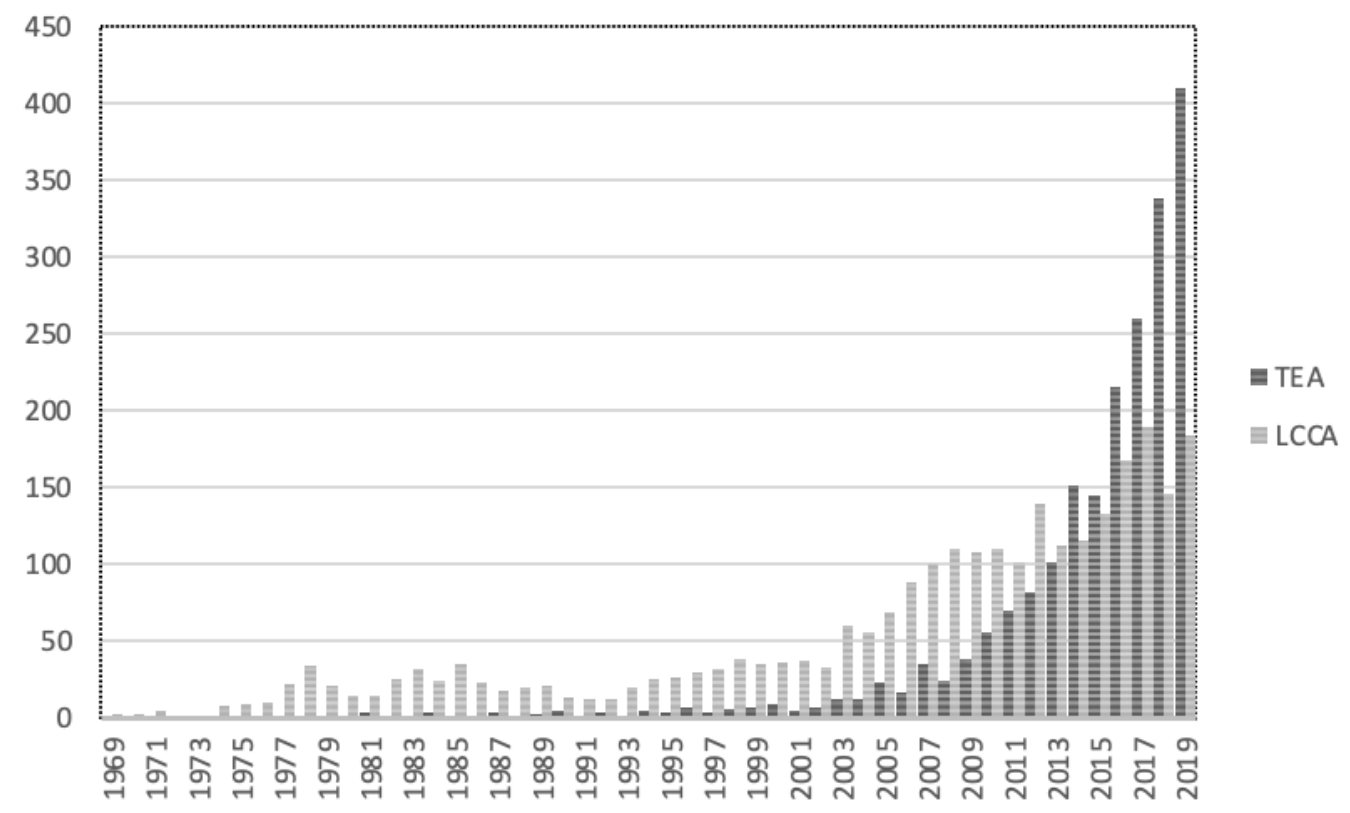

Figure 1: Publications per year on TEA and LCCA

Source: Scopus database (March 2020) 
INSIGHTS INTO REGIONAL DEVELOPMENT

ISSN 2669-0195 (online) http://jssidoi.org/jesi/

2021 Volume 3 Number 2 (June)

http://doi.org/10.9770/IRD.2021.3.2(2)

In the second phase, the distinctive elements of TEA and LCCA were identified on the basis of the most recurrent theoretical concepts and methodological elements in the revised literature. It goes without saying that conducting an in-depth analysis for almost five thousand articles was not realistic. Therefore, reference has been made to limited set of articles. This further selection was conducted taking into consideration only those articles whose main focus was theoretical and / or methodological, and which presented particular interest for a methodological discussion. In addition, we also considered the inclusion of complementary sources (i.e. grey literature) to obtain a more accurate and complete reference base. Amongst the more relevant implementations: Fabrycky and Blanchard (1991), Van Dael et al. (2015), Zimmerman et al.(2018), Rajendran and Murthy (2019).

Finally, in the last phase of the research, the focus has turned to real case studies in order to verify the existence, completeness and appropriateness of those methodological elements outlined formerly. Base on a combination of our previous researches on Scopus, a new list of studies was retrieved. The research was performed accordingly to those publications which elements simultaneously belonged, entirely or partially, to both evaluation methods. The records were gathered using the following string:

TITLE-ABS-KEY ((“Techno-Economic Assessment" OR "Techno-Economic Evaluation" OR "TechnoEconomic Analysis") AND ("Life Cycle Cost" OR "Life Cycle Costing"))

From this, a preliminary list of 77 studies was obtained. Further, a primary analysis of the abstracts was carried out to exclude inappropriate studies and inaccessible sources. Since the research was strictly aimed at real case studies, articles concerning reviews, general discussion of the methods, analysis of specific elements - e.g. uncertainty - or delineation of supporting material - e.g. costs database - were, this time, excluded from the list. As a result, 25 papers out of 77 resulted coherent with the objective of the analysis. From this reference set, a categorisation and reorganisation of contents allowed to identify possible sources of misunderstanding, as well as similarities, differences and opportunities for integration.

\section{TEA: methodological steps and distinctive elements}

Literature lacks a pure theoretical discussion on the methodological setting for TEA, which appears weak and almost inexistent. Most of the information need to be gathered by specific industry reviews and exclusive studies on particular technological fields. This deficiency forces to derive the conceptual structure of the method mostly by sectorial specific guidelines which, however, results considerably oriented towards specific industrial specificities.

The inspection of selected references produced the categorisation of the six following methodological steps, from which the distinctive elements are derived:

i. $\quad$ Definition of technology readiness levels (TRL);

ii. identification of system elements and boundaries;

iii. study of economic feasibility, costs and market conditions;

iv. profitability analysis;

v. risk and uncertainty analysis through sensitivity and scenario forecasting;

vi. recommendations. 
Technology readiness assessment and TRL.

Generally, a project is completed because of subsequent successful technical improvements through its entire development. For this reason, the maturity and/or capability of a technology need to be constantly tested. According with Mankins (2009), the moments in which this verification happens take the name of technology readiness assessments (TRAs). Through TRAs, other than defining the technology readiness level (TRL) it is also possible to provide reliable evaluations on riskiness of project progress.

As for techno-economic assessment, the readiness level of a project influences not only assumptions, quality and availability of data, but also and foremost the decisions of metric and consequently results and interpretability (Zimmerman et al., 2018). It follows that determining TRL is a fundamental and distinctive element in the iterative process of TEA and its analysis needs to be performed in the very first step of the evaluation procedure. Further, its constant review and adjustment should accompany the entire project. Recently, technology readiness levels have been proposed as a backbone of TEA by Buchner et al. (2018). Based on TRLs, in fact, the authors were able to sort several cost estimation methods, profitability indicators and approaches to the market analysis for each level.

However, an appropriate analysis of TRLs is not straightforward since multiple elements and heterogeneous "subtechnologies" may define the overall project, requiring lot of effort to properly assess the components individually. Enhancing comparability among different studies may ease and expedite such an assessment.

Below, Table 2 recollects the specific definitions for each development stage, accordingly with each technology readiness level.

Table 2: Technology readiness level scale

\begin{tabular}{|c|c|c|}
\hline Level & Development phase & Definition \\
\hline TRL 1 & Research & Observation of basic principles. \\
\hline TRL 2 & Research & Conceptual formulation of the technology. \\
\hline TRL 3 & Research & Concepts are proved experimentally. \\
\hline TRL 4 & Development & Laboratory validation of the technology. \\
\hline TRL 5 & Development & $\begin{array}{l}\text { Validation of the technology in relevant } \\
\text { environment (industrially relevant environment } \\
\text { in the case of key enabling technologies). }\end{array}$ \\
\hline TRL 6 & Development & $\begin{array}{l}\text { Demonstration of the technology in relevant } \\
\text { environment (industrially relevant environment } \\
\text { in the case of key enabling technologies). }\end{array}$ \\
\hline TRL 7 & Deployment & $\begin{array}{l}\text { Prototype demonstration in operational } \\
\text { environment. }\end{array}$ \\
\hline TRL 8 & Deployment & System complete and qualified. \\
\hline TRL 9 & Deployment & $\begin{array}{l}\text { Prove of the actual system in operational } \\
\text { environment (competitive manufacturing in the } \\
\text { case of key enabling technologies). }\end{array}$ \\
\hline
\end{tabular}

Source: Horizon 2020, General Annex-G

\section{System elements and boundaries.}

In life-cycle assessment (LCA) the product system identifies the "collection of unit processes with elementary and product flows, performing one or more defined functions, and which models the life cycle of a product' (ISO 14040:2006). Each activity in the system, be it a unit process, operation or equipment, is a system element 
INSIGHTS INTO REGIONAL DEVELOPMENT

ISSN 2669-0195 (online) http://jssidoi.org/jesi/

2021 Volume 3 Number 2 (June)

http://doi.org/10.9770/IRD.2021.3.2(2)

(Zimmerman et al., 2018) and it is coherently defined within the system boundaries. Identifying system elements and system boundaries is of primary importance for TEA. In fact, their description is a fundamental operation when input and output flows are determined, as well as in analysing interconnections among elements and phases of the project's development. Overall, this analysis takes the name of product system analysis.

System boundaries are essential to delineate the processes and operations to be taken into account when analysing the product system. Also, they are useful to revise what is included in the analysis and, at the same time, give consistent elements for a transparent comparison with benchmark systems and other TEA studies (Zimmerman et al., 2018). It is important to consider that, not only the definition of boundaries requires large amount of data, time and economic resources (Reap et al., 2008), but it is also sensible to subjective considerations that makes necessary a transparent communication of assumptions and defining criteria (Jensen et al., 1998). Amongst the most diffused settings are the gate-to-gate, cradle-to-gate and cradle-to-grave. These respectively indicate the inclusion or not of the several lifecycle stage of a project. From the narrower (Gate-to-Gate), which mainly focuses on specific modules of the project's development, to the broader Cradle-to-Grave where all stages of the lifecycle of a project are addressed, from the extraction of materials to the disposal/recycling time (Torabi \& Ahmadi, 2020). It is worth noting that setting broad enough boundaries - e.g. cradle to grave - may provide a contact between TEA and LCCA, since it can associate them to a common lifespan of interest.

Similarly, also the process flow diagram (PFD) is common for TEA. Its implementation gives a graphical representation of the objects under analysis but, other than exploring elements and connections, it can also include mass and energy balance of a process (Van Dael et al., 2013, 2015). This additional characteristic allows a direct estimation of expenses, such as operational costs (Buchner et al., 2018) and, at the same time provide with a more inclusive representation of the true performances of the project. However, with respect to the more general product system analysis, the PFD requires more sophisticated computations, higher efforts and specific competences of analysts. To note that, in some cases (Michailos et al., 2018; Zimmermann et al., 2019), the product system analysis may acquire the nature of a preliminary step in the PFD definition, but also that the first iterations of PFD may present just a block scheme structure (Van Dael et al., 2015), similarly to a product system. On this basis, it is reasonable to think about the PFD as a sort of ultimate and most detailed characterisation of a product system analysis.

\section{Cost analysis and market conditions}

Together with technical viability, determining economic feasibility is the other main purpose of TEA. However, determining if the project is worth the investment (profitability analysis) requires a previous evaluation and examination of costs and conditions which may affect the accomplishment of the project's objective.

The evaluation of the economic conditions in a techno-economic study starts from costs and market conditions. These are strongly interconnected elements which have a mutual effect in perfectionating and determining each other (Buchner et al., 2018). On the one hand, evaluating market conditions supports the understanding and proper identification of expenditures; on the other hand, the cost breakdown may reveal new market sensibilities and drive future iterations of market analysis. However, for both analyses different approaches exist. As a matter of fact, the evaluation of expenses is approached with several different estimation tools and practices, while the market analysis can show up at different stages of the evaluation process and be motivated by different purposes. As exposed in Buchner et al. (2018), TRLs may provide a reasonable guide to clarify how and when these two essential analyses should be implemented.

Following, the theme of market analysis and cost estimation are treated separately. 
INSIGHTS INTO REGIONAL DEVELOPMENT

ISSN 2669-0195 (online) http://jssidoi.org/jesi/

2021 Volume 3 Number 2 (June)

http://doi.org/10.9770/IRD.2021.3.2(2)

\section{Market analysis}

Market analysis is sometimes proposed as the very first step in the techno-economic assessment (Kantor et al., 2010; Van Dael et al., 2015). In these cases, the analysis looks for competitors, customer preferences, size, trends and needs of the market, as well as preliminary information about costs, revenues and critical success factors. However, the best approach to market analysis needs to consider the overall level of advancement of the project. If implemented too early or too late, with respect to its best placement, the analysis may be inconsistent with data. In other words, the market analysis may result in excessive, or insufficient information and cause an inefficient allocation of resources. As previously anticipated, relying on TRL may drive practitioners during the market analysis. The design, the level of detail and the point in time at which the market evaluation take place can all rely on the grade of technological development in order to respect the most efficient arrangement. However, until a clear TRL-based scale is developed, practitioners will mostly rely on personal knowledges and specific characteristics of the case. Table 3 summarises, in relation with cost estimation, the most appropriate phase to perform market analysis and the main constitutive elements.

Table 3: An introductory TRL-based framework for market analysis in TEA

\begin{tabular}{llll}
\hline TRL levels & Phase & Elements \\
\hline $\begin{array}{l}\text { TRL } \\
\text { (Research) }\end{array}$ & $1-3$ & Before cost estimation & $\begin{array}{l}\text { Need of the market, } \\
\text { comparison with alternatives } \\
\text { and benchmarks }\end{array}$ \\
\hline $\begin{array}{l}\text { TRL } \\
\text { (Development) }\end{array}$ & $4-6$ & Parallel to cost estimation & $\begin{array}{l}\text { Sales prices and volumes, } \\
\text { market size, customer } \\
\text { preferences }\end{array}$ \\
\hline $\begin{array}{l}\text { TRL } \\
(\text { Deployment })\end{array}$ & $7-9$ & Individual analysis & $\begin{array}{l}\text { Trends, entry strategies, } \\
\text { SWOT analysis, Volume } \\
\text { chain analysis }\end{array}$ \\
\hline
\end{tabular}

Source: excerpted from Buchner et al. (2018)

In early stages what should be investigated are the main opportunities and space for the technology, together with a first identification of alternatives and benchmarks. In this case the market analysis should precede the cost estimation and support a preliminary analysis of expenses. Following, as the TRL advances more specific examinations should consider aspects such as: prices, volumes, and customer preferences but, differently from before, the market and cost analysis would work synergistically and being performed in parallel. Finally, the market analysis may assume an individualistic profile and address more specifically the entrance in the market.

\section{Cost estimation}

On the other edge of the economic evaluation, cost estimation is central for TEA. In its broader meaning, it aims to quantify total costs on the basis of operational (OpEx) and capital (CapEx) expenditures. Usually, the first refer to recurring costs that necessarily emerge for the maintenance and operativity of a project, while in the latter all costs that protract their effects through time, such as designing, constructing or commissioning expenses converge and define the aggregate. As for capital and operational expenses, both can be broken down into their constitutive elements, providing additional information for further analysis on profitability. Moreover, their combination can provide informative aggregates such as: cost of good manufactured (COGM) and cost of goods sold (COGS). While COGM and COGS are essential figures in cost management and accounting procedures, they are limited in projects with a strong productive nature. On the other hand, the life-cycle cost (LCC) is a more common figure 
but, rather than a mere aggregate, it should be intended as the result of the LCCA. This distinction is particularly relevant since it is during the cost evaluation step that most of the misperceptions around LCCA and TEA emerge, producing misleading implementations of the first method and an ambiguous adoption of terminology. It is straightforward that, conformably with the development stage of the project and quality of information, several approaches can be adopted to evaluate costs, each with different levels of complexity and reliability. According with the Cost Estimate Classification System by the Association for the Advancement of Cost Engineering (AACE International), five types of costs estimates can be defined, each differing in aspects such as the maturity level of the project, the purpose of the estimate or the accuracy. The five classes of estimates are summarised in Table 4 Also, we propose a hypothetical correspondence with technology readiness levels.

Table 4:Cost estimate classification and characteristic

\begin{tabular}{|c|c|c|c|c|}
\hline Type of estimate & $\begin{array}{c}\text { Maturity level } \\
\text { of the project } \\
\text { (\% of complete } \\
\text { definition) }\end{array}$ & TRL & $\begin{array}{l}\text { Purpose of the } \\
\text { estimate }\end{array}$ & Accuracy \\
\hline $\begin{array}{l}\text { Order of } \\
\text { magnitude } \\
\text { estimate (ratio } \\
\text { estimate) }\end{array}$ & $0 \%$ to $2 \%$ & 1 to 3 & Concept screening & $\begin{array}{l}\text { L: }-20 \% \text { to }-50 \% \\
\mathrm{H}:+30 \% \text { to }+100 \%\end{array}$ \\
\hline $\begin{array}{l}\text { Study estimate } \\
\text { (factored } \\
\text { estimate) }\end{array}$ & $1 \%$ to $15 \%$ & 3 to 5 & Study or feasibility & $\begin{array}{l}\text { L: }-15 \% \text { to }-30 \% \\
\mathrm{H}:+20 \% \text { to }+50 \%\end{array}$ \\
\hline $\begin{array}{l}\text { Preliminary } \\
\text { estimate }\end{array}$ & $10 \%$ to $40 \%$ & 4 to 7 & $\begin{array}{l}\text { Budget authorization, } \\
\text { or control }\end{array}$ & $\begin{array}{l}\text { L: }-10 \% \text { to }-20 \% \\
\mathrm{H}:+10 \% \text { to }+30 \%\end{array}$ \\
\hline $\begin{array}{l}\text { Definitive } \\
\text { estimate (project } \\
\text { control estimate) }\end{array}$ & $30 \%$ to $70 \%$ & 7 to 8 & Control & $\begin{array}{l}\mathrm{L}:-5 \% \text { to }-15 \% \\
\mathrm{H}:+5 \% \text { to }+20 \%\end{array}$ \\
\hline $\begin{array}{l}\text { Detailed estimate } \\
\text { (contractor's final } \\
\text { cost estimate) }\end{array}$ & $50 \%$ to $100 \%$ & 8 to 9 & Check estimate & $\begin{array}{l}\mathrm{L}:-3 \% \text { to }-10 \% \\
\mathrm{H}:+3 \% \text { to }+15 \%\end{array}$ \\
\hline
\end{tabular}

Source: excerpt from Christensen and Dysert (2005) and Coker (2007)

Obviously, "cost estimation" belongs to the overall discipline of economic evaluation and a multitude of tools and approaches have been developed to break and estimate expenses. Due to this variability, every case needs specific considerations in order to identify the solution which best fits with the purpose of the evaluation. Even if developed for the chemical industry, a good exposition of relevant cost estimation tools is provided by Coker (2007).

In conclusion, it is worth noting that, still recognizing the fundamental importance of the assessment of costs, it should not be performed at the expense of other elements of the entire analysis. In other words, who perform the techno-economic assessment needs to balance all the necessary elements and do not concentrate the majority of resources to evaluate the expenses, while leaving poor, or insufficient considerations to other parts of the analysis, such as market or profitability analysis. 


\section{Profitability evaluation}

Consequence of gathering and examining costs and market conditions, is the profitability analysis. Profitability analysis looks for monetary gains (or losses) and usually compares them with alternatives and/or thresholds. Overall, it guides decisions about the allocation of resources and the definition of investments (Buchner et al., 2018). Also, it offers a significant qualitative view about the economic performances of the project, adding insights on the project's development.

Generally, the profitability of a project is judged comparing earnings and costs, but this information rarely gives enough evidence for a conscious decision and additional metrics are needed. However, identifying and deciding about profitability indicators is challenging due to lack of standardization; further, the wide range of possibilities makes proper decisions harder. Practitioners mostly need to decide without clear instructions, leaving space to biases due to subjective comprehensions and personal preferences. Again, Buchner et al., (2018) gives interesting directives to decide the best profitability indicators according with the advancement of the project. These are summarised in Table 5 below.

Table 5: Profitability indicators and TRL

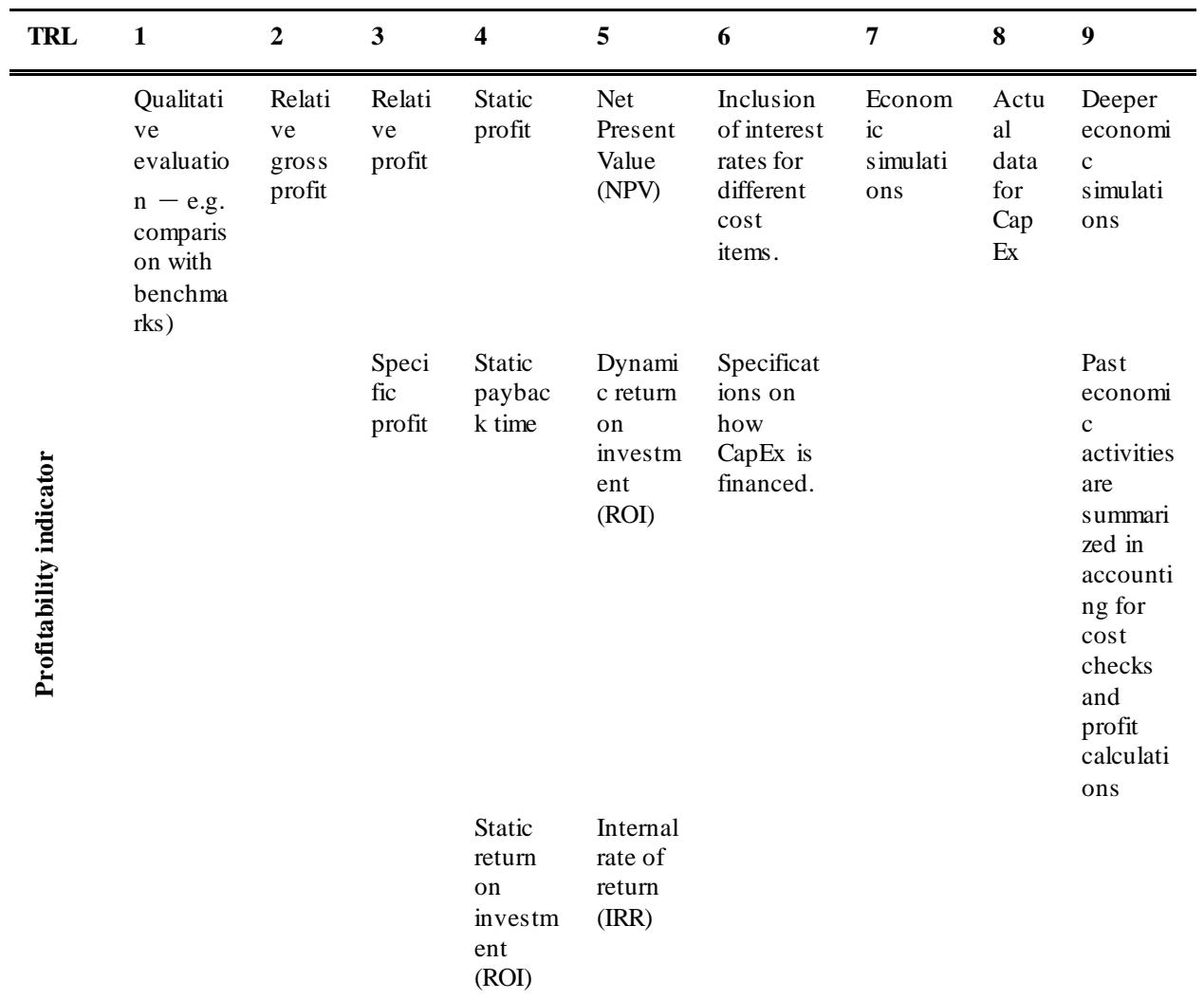


INSIGHTS INTO REGIONAL DEVELOPMENT

ISSN 2669-0195 (online) http://jssidoi.org/jesi/

2021 Volume 3 Number 2 (June)

http://doi.org/10.9770/IRD.2021.3.2(2)

Uncertainty: sensitivity and scenario analysis

Every evaluation developed on assumptions and estimates inevitably produces uncertainty in results. For TEA, uncertainty is mainly caused by errors in input data, uncertainties in the model itself, and the characteristics of the context in which the analysis is performed (Zimmerman et al., 2018). The inspection of uncertainty represents the last methodological steps of a techno-economic analysis.

The necessity for uncertainty analysis is due to the fact that that decision makers need to be informed on the reliability of positive results, as well as on which technical and economic parameters have the potential to influence most the profitability of a project (Kuppens et al., 2015). Accordingly, there are two main tools usually embraced to deal with TEA's uncertainty: sensitivity analysis (SA) and scenario analysis. SA identifies the portion of uncertainty in the output caused by different model input factors (Helton et al., 2006; Saltelli et al., 2010). Further, the SA can take the form of a "local" or "global" analysis (Haaker \& Verheijen, 2004). The first considers 'how much of the output is changed by a small variation of the random input around a reference point', while the latter 'measures the contribution of an individual random input to the output within the entire range space of the input' (Tang et al., 2015). In other words, while the local SA looks how outputs are influenced by singular variations of inputs, a global SA considers multiple and simultaneous variants. Scenario analysis, on the other hand, does not specifically address the uncertainty of parameters, but rather considers contextual variations and possible future events that may affect results. It is usual to set three possibilities for the uncertain variables: a pessimistic, a most excepted and an optimistic scenario. According to Van Dael et al. (2015), through scenario analysis it is possible to deduct information about maximal economic loss, but also about the expected value of benefits, in case probabilities of occurrence can be determined

In the following section the same approach of analysis is adopted to go more in deep into the distinctive elements of the LCCA. By adopting the same approach confrontation results easier. Furthermore, it consents to critically revise differences and similarities on the basis of a more unbiased standpoint.

\section{LCCA: methodological steps and distinctive elements}

As already noted, the LCCA is an older evaluation method than TEA. Practitioners can count on more reliable references, identifiable in specific guidelines and sectorial standards and also benefit from a harmonisation with the well-defined LCA framework (ISO 14040:2006). However, differently from the LCA, and at the same way of TEA, the LCCA have not achieved any complete standard and the proposed guidelines still fail to define a universal and flexible framework, able to clearly state the distinctive elements of the tool, their characteristics of application and a clear procedural approach.

Source of this misalignment between theoretical conception and practical approach is due to the fact that, instead of defining a complete hypothetical structure, the method has been diffused and implemented through years to address specific industrial issues (Sherif \& Kolarik, 1981), leaving individualities of cases, subjective considerations and sectorial characteristics guiding the adoption of the LCCA. European practitioners, in the specific, can count on several industrial-specific national and international regulations, such as the Norwegian standard NS 3454, the UK procurement guide 07 or the ISO 15686-5: 2017 for the building industry, while the ISO 15663:2000 is a reliable reference for the petroleum and natural gas business. Langdon (2007) can be consulted for a deeper view on some relevant LCCA guidelines. However, out of these sectors LCCA mostly rely on subjective analyses and variations.

It is straightforward that systematising the method, independently from the sector, may ease adoption and diffusion, facilitating also a reliable comparison of studies. However, also standardization needs to deal with some issues and controversy. On the one hand, the absence of a universal recognition by the industry represents one of 


\section{INSIGHTS INTO REGIONAL DEVELOPMENT}

ISSN 2669-0195 (online) http://jssidoi.org/jesi/

2021 Volume 3 Number 2 (June)

http://doi.org/10.9770/IRD.2021.3.2(2)

the main barriers for reliable and consistent data (El Haram et al., 2002). On the other hand, homogenising specific cost figures is unlikely to match with individual cost systems and may result to negatively affect the overall methodology (Hunkeler et al., 2008). For these reasons, the homogenisation process should focus on defining the methodological structure of the method, allowing for a sufficient level of adaptability in those aspects which cannot be standardised but that still can be regulated by some criteria - e.g. selecting cost breakdown structure.

All this considered, only if a transparent and coherent methodological framework is in place the method can progress and become adaptable. A balanced homogenisation should not prevent the effectiveness of LCCA applications, rather it would guide LCC-users in the correct combination and/or selection of critical features according to their needs. Ultimately, a clearer identification and estimation of methodological components of LCCA represents a way to improve interpretability and comparability of studies.

Following the elements of the LCCA are explored based on two main groups of references: theoretical studies and "standards \& guides". Particular attention has been given to certain methodological frameworks (Fabrycky \& Blanchard, 1991; Woodward, 1997), for which insights and practical steps are summarised in TABLE X, and the "Life-cycle costing Manual" for energy projects by Fuller and Petersen (1996).

Table 6: Summary of Fabrycky-Blanchard and Woodward methodological proposals

\begin{tabular}{ll}
\hline Fabrycky and Blanchard (1991) & Woodward (1997) \\
\hline \hline Insights & $\sim$ Optimization and minimum life cycle cost \\
$\sim$ Importance of alternatives & $\sim$ Discounting and inflation \\
$\sim$ Cost break down and categorization & \\
\hline Practical steps & 1.Establishment of operation profiles \\
1.Definition of the problem & 2.Establishment of utilization factors \\
2. Identification of feasible alternatives & 3.Identification of cost elements or area of \\
3. costs \\
4. Selection of a Cost model for analysis
\end{tabular}

Source: excerpt from (Fabrycky \& Blanchard, 1991; Woodward, 1997), 
INSIGHTS INTO REGIONAL DEVELOPMENT

ISSN 2669-0195 (online) http://jssidoi.org/jesi/

2021 Volume 3 Number 2 (June)

http://doi.org/10.9770/IRD.2021.3.2(2)

Coherently with other studies in literature (Cole \& Sterner, 2000; Fisher, 1970), the following methodological steps are identified for LCCA:

i. $\quad$ Definition of object, problems and alternatives;

ii. analysis of costs (cost breakdown, selection of cost modelling and estimation);

iii. economic evaluation and discounting future cash flows;

iv. considering risk and uncertainty

v. comparing alternatives.

\section{Object, problems and alternatives}

In its very first stages, LCCA needs to clearly identify the objects and problems which wants to address. While the detection of problems is directly attributable to purposes of the study and answers to the question "Why the study?", the objects definition refers to the physical entity of the analysis addressing the problem of "What is studied?". In this phase, all relevant information and assumptions have to be outlined, together with a welldefined identification of the boundaries-system and objectives. The identification of boundaries-system may follow the same considerations already moved for TEA that will not be repeated. We stress again the relevance that boundaries system may have as a connective force for the two methods under analysis. Following, the discussion about the objectives.

Fundamental in this early stage of the process evaluation is clearly state the aims of the LCCA. The LCC Manual by Fuller and Petersen (1996) provides a list of possible reasons that may motivate a study of life cycle costing:

- Acceptance or rejection of single projects or system option,

- $\quad$ selection of optimal solutions among alternatives, and

- $\quad$ ranking of different projects

It is straightforward the relevance of alternatives. Most of the times, LCCA is used to identify the most costefficient option among a series of alternatives and/or design solutions. According to the international standard for buildings and constructed assets, in fact, the LCCA 'allows consistent comparison to be performed between alternatives with different cash flows and different time frames' (ISO 15686-5:2017).

It follows that the identification of alternatives is a distinctive element of the LCCA, which become essential in the design stages, when the LCCA planning is performed (Hunkeler et al., 2008). Feasible alternatives need to be decided on the basis of technical features with potential economic consequences (Fuller \& Petersen, 1996). Identifying technically sound and practical alternatives need to be consistent with both techno-economic constraints and the objects of the analysis. A detailed analysis of technical performances may take a cue from TEA, even if the same level of detail is no required.

\section{Cost analysis}

Once the LCCA is profiled, estimating and categorising costs follows. In its nature, the life-cycle cost analysis looks at expenses with a broader-than-usual perspective by considering all relevant life-cycle stages of a project. In this way a more realistic representation of the economic state is possible. However, practitioners still seem hesitant to accurately include very early/late phases of the lifecycle, such as $R \& D$ and disposal phases in their analyses. 
INSIGHTS INTO REGIONAL DEVELOPMENT

ISSN 2669-0195 (online) http://jssidoi.org/jesi/

2021 Volume 3 Number 2 (June)

http://doi.org/10.9770/IRD.2021.3.2(2)

Evidently, as it is the case for TEA, a costs breakdown is necessary to detect the nature and consistency of the expenses involved in the project. Since the dependency on specific needs of practitioners, as well as characteristics of the operational environment, the structures proposed in literature vary in their perspective and spotlights. It follows that costs may be classified in accordance with the distinctive stages of a project, as in the case of some wind farm evaluations (Mytilinou et al., 2018; Shafiee et al., 2015), but also with the typology, manifestation in time and rate of recurrence (Fuller \& Petersen, 1996). Similarly, the theoretical frameworks by Fabrycky \& Blanchard, (1991) recommended a cost classification linked with the specific life-cycle stage, while in Woodward (1997), it is the nature of the expenses to drive their definition.

Finally, an interesting "five-levels" breakdown structure comes for the British Standard 5760: part 23:1997 on the reliability of systems, equipment and components. The framework has the peculiarity to propose a cost categorisation which evolves with the development of the project or product. In this framework each consecutive phase enhance the details and broaden the typologies of costs considered (El Haram et al., 2002). Starting by detecting a limited set of cost categories which can be allocated to the overall project, the costs are further grouped with regard to the life cycle phase, cost category, elements, tasks (or activities) and specific resources expenses, deepening the analysis and including increasing groups of costs.

\section{Time discounting}

Discounting is a pivotal distinctive element for LCCA, and its proper adoption is crucial for consistent results. As pointed out by Woodward (1997), poorly projecting costs may introduce inaccuracy in calculations. Furthermore, process of discounting back at a base period provides a common base for comparison of alternatives, while concurrently reflect the implications of time.

In practice, all influences of time are condensed into a specific parameter, the discount rate. However, its definition is challenging, and lot of theoretical discussion exist proposing multiple discount functions and approaches - e.g. hyperbolic discount function, null discount rate and decreasing discount function). While it is not the purpose of this research to investigate their theoretical backgrounds, for our purposes we deemed important to distinguish between real and nominal discount rates. Real discount rates are netted out of inflation and are used with constant-currency amounts; on the other hand, nominal discount rates include general inflation and are used with current-currency amounts (Fuller \& Petersen, 1996). To note that, if nominal rates are used inflation should still be treated separately since lacking to consider variation in costs may importantly affect results.

Typically, discount rates range from 5 to 20 percent for private and corporate investments, whilst for the public sector rates may be lowered up to 2 per cent (Hunkeler et al., 2008; Zizlavsky, 2014). However, setting the correct rate is challenging and, even if some specific national legislations and sectorial recommendations exist, lot is left to personal judgments of those who operate the study.

\section{Economic evaluation}

As a result of the discounting process, the net present value (NPV), also referred to as net present cost or sometimes life-cycle cost (LCC), aggregates all future discounted cash flows into a unique figure and representatively indicates the economic performances of a project. It is computed as:

$$
\text { Net Present Value }(N P V)=\frac{\sum_{t=0}^{\mathrm{T}}\left(\mathrm{C}_{\mathrm{t}}-\mathrm{B}_{\mathrm{t}}\right)}{(1+\mathrm{d})^{\mathrm{t}}}=\frac{\sum_{\mathrm{t}=0}^{\mathrm{T}}(\mathrm{NCF})}{(1+\mathrm{d})^{\mathrm{t}}}
$$


INSIGHTS INTO REGIONAL DEVELOPMENT

ISSN 2669-0195 (online) http://jssidoi.org/jesi/

2021 Volume 3 Number 2 (June)

http://doi.org/10.9770/IRD.2021.3.2(2)

where, $\mathrm{T}=$ total life cycle in years, $\mathrm{t}=$ time (year), $\mathrm{C}=$ future negative cash flows (future costs), $\mathrm{B}=$ future positive cash flows (future benefits), $\mathrm{d}=$ discount rate and $\mathrm{NCF}=$ net cash flow.

However, the NPV is not the only evaluation criteria used in the LCCA. In fact, while providing a preliminary view of the excepted economic performances of the project under analysis, it is also the base to determine other explicative measures, such as: the internal rate of return (IRR), net savings (NS), savings to investment ratio (SIR) and discounted payback period (DPP). Although, it is not aim of this research to enter the analysis of such measurements, explanations and adoption procedures can be found in the studies by Fuller and Peterson (1996) and Langdon (2007).

\section{Uncertainty and risk analysis}

As it is the case of TEA, LCCA need to address the uncertainty issue. As a reminder, uncertainty analysis explicates the overall alteration of results caused by statistical uncertainty of probabilistic events and the future state of the world. General observations previously moved for TEA are still valid. Uncertainty analysis is a major and necessary concern that allows for a correct interpretation of results, as well as highlighting the most influencing parameters and their relationships with results. As for LCCA, the most common sources of uncertainty are identifiable in: errors in estimations, technological advancement, fluctuations in price levels and inflation, differences between expected and actual performances and changes in operational assumptions (Woodward, 1997).

In LCCA literature deterministic and non-deterministic, or probabilistic, approaches for analysing uncertainty are common. The deterministic approach - e.g. local sensitivity- represents the easiest way to measure the effects of changes in one, or multiple key values. Input parameters are introduced as discrete values and no probability distributions are present. On the other hand, non-deterministic methods - e.g. global sensitivity - consider probabilistic distributions of events to determine weighted averages, expected values and other statistical indicators, as well as allowing all significant input parameters to change simultaneously (Diependaele, 2018). Still representing a more explicative and complete approach, probabilistic inferences require more sophisticated analyses, as well as broader quantity of data and resources, in terms of time, money and expertise (Fuller \& Petersen, 1996). Due to this, the majority of cases adopts non-deterministic methods that, however, result more mutable to subjective considerations. Probabilistic approaches are not deeply investigated here, while some attention is given to the deterministic methods of sensitivity and breakeven analysis.

Sensitivity analysis (SA) and breakeven analysis (BEA) are amongst the most common methods used by practitioners to approach uncertainty in LCCA. The "LCC Manual" provides a good explanatory practical guide for both these tools. At the same way of TEA, the sensitivity analysis is used to investigate how changes in key assumptions or parameters - e.g. prices - alter the performances of the project. Input values are moved around a reference number making clear the changes in results. Major influencing parameters can be ranked and further analysed through scenario analysis (Diependaele, 2018), which would also help to define a possible range of values among sensible indicators, usually upper, medium and lower bound. However, differently from TEA, which seems to adopt a broader approach addressing contextual factors such as institutional frameworks, subsidies, etc., sensitivity analysis in LCCA generally focus on cost-related parameters.

Break-even analysis (BEA), on the other hand, emphasises the maximum or minimum value of a crucial factor for maintaining the break-even (Fuller \& Petersen, 1996). In this case the assessment is determined by solving a simple equation: operational savings and additional investment related costs are equalized, and all but breakeven variables are specified. 
INSIGHTS INTO REGIONAL DEVELOPMENT

ISSN 2669-0195 (online) http://jssidoi.org/jesi/

2021 Volume 3 Number 2 (June)

http://doi.org/10.9770/IRD.2021.3.2(2)

\section{Operational Savings $=$ Additional investment related costs}

$$
\mathrm{S}=\Delta \mathrm{C}
$$

Deterministic methods are valid approaches for uncertainty analysis; however, as much as the maturity of the project is advanced, some limitations may affect their efficiency. In fact, at least three shortcomings can be identified with regard to deterministic analyses (Langdon, 2007): firstly, the impossibility to identify the best alternative when the ranking is affected by changes in model variables; secondly, local sensitivity approaches may reduce the interpretability of combined and simultaneous influences on final results; finally, probability distribution or likelihood of outcomes are not considered making the reliability of results impossible to evaluate. Non-deterministic methods may partially overcome these issues.

\section{Towards an integrative approach}

Whilst the techno-economic assessment and the lifecycle cost analysis share the same reason of existence: providing a more inclusive and reliable evaluation method for a better allocation of resources, their approach and objective is somewhat different. Recalling what previous, TEA aims to simultaneously consider economic and technical performances of a project so that sensible elements can be detected, and adjustments taken. On the other hand, the main intention of the LCCA is to appraise the best among different solutions based on costs considerations. However, several studies rely on a simultaneous adoption of such tools but without the possibility to rely on any sort of regulation. For this reason, it seems appropriate to investigate and discuss on which elements and aspects TEA and LCCA converge or diverge, in order to give a basis for objectively evaluate a potential integrative and methodical approach.

Following, Table 7 offers, in a compact form, the main points of convergency/divergency between the two evaluation methods. Such a distinction is based on the main concepts analysed through the text; however, still recognising the potential validity of such theoretical assumptions, in practice clear distinctions is missed.

Table 7: Convergencies and divergencies between TEA and LCCA

\begin{tabular}{|c|c|c|c|}
\hline Elements & Convergency & Divergency & Description \\
\hline Uncertainty & - & & $\begin{array}{l}\text { Similar process. Distinctive of TEA is the } \\
\text { scenario analysis, while breakeven analysis for } \\
\text { LCCA. }\end{array}$ \\
\hline Boundaries & $\bullet$ & & $\begin{array}{l}\text { Same definitional approach. LCCA may be } \\
\text { adopted to expand the perspective into a more } \\
\text { appropriate cradle-to-grave. }\end{array}$ \\
\hline Cost analysis & $\bullet$ & & $\begin{array}{l}\text { In TEA may be sufficient to generally } \\
\text { identified CapEx and OpEx. LCCA provide a } \\
\text { more detailed analysis of these costs. }\end{array}$ \\
\hline Market analysis & $\bullet$ & & $\begin{array}{l}\text { Should be explicit in TEA. Not specifically } \\
\text { required for LCCA. But could be consider } \\
\text { implicit. }\end{array}$ \\
\hline $\begin{array}{l}\text { Profitability } \\
\text { analysis }\end{array}$ & $\bullet$ & & $\begin{array}{l}\text { Same approach to the determination of } \\
\text { economic feasibility but different metrics. }\end{array}$ \\
\hline $\begin{array}{l}\text { Benchmarks } \\
\text { and alternatives }\end{array}$ & & $\bullet$ & $\begin{array}{l}\text { While TEA mainly rely and identify particular } \\
\text { technological benchmarks, LCCA main } \\
\text { reference is given by alternatives. }\end{array}$ \\
\hline
\end{tabular}


INSIGHTS INTO REGIONAL DEVELOPMENT

ISSN 2669-0195 (online) http://jssidoi.org/jesi/

2021 Volume 3 Number 2 (June)

http://doi.org/10.9770/IRD.2021.3.2(2)

\begin{tabular}{|c|c|c|}
\hline Focus & $\bullet$ & $\begin{array}{l}\text { TEA strongly focus on the relationships } \\
\text { between techno and economic performance. } \\
\text { LCCA is mostly used in for evaluating and } \\
\text { ranking alternatives. }\end{array}$ \\
\hline Inflation & $\bullet$ & $\begin{array}{l}\text { In the computation of costs for LCCA. } \\
\text { Analysed through scenario analysis in TEA. }\end{array}$ \\
\hline $\begin{array}{l}\text { Technological } \\
\text { aspect }\end{array}$ & $\bullet$ & Present in TEA only. \\
\hline Time & $\bullet$ & $\begin{array}{l}\text { Forecasting (TEA) and actualization process } \\
\text { (LCCA). }\end{array}$ \\
\hline TRL & $\bullet$ & Not present in LCCA, essential for TEA. \\
\hline
\end{tabular}

Source: own elaboration

Main theoretical divergencies concerning TEA and LCCA are identified in the adoption of technology readiness assessments for the analysis of TRL, the different attention to time and inflationary effects. Also, the adoption of benchmarks, for TEA, and alternatives, for LCCA, is a characteristic which distinguish the methods in the way they recognise the results. As for TRL, we already had the chance to note its significance for techno-economic analysis due to the opportunity it offers in guiding decisions about several characteristics of the assessment. Same importance is not acquired by TRL for the analysis of the life cycle costing. Next, regarding the approach to time it could be stated that, while TEA ought to be more concerned about forecasting of exogenous events - e.g. scenario -, LCCA is be more committed to an actualization process. In other words, while TEA usually projects the future, LCCA brings it back to a current meaning. Finally, inflation is apparently addressed in different ways by the two methods, in fact, while in LCCA it should be integrated during the computation of costs, in TEA the volatility of prices is mostly addressed through scenario analysis.

With respect to the points of convergency, most are identified in the economic analysis expected by the methodological frameworks and the setting of the boundaries system. The latter aspect is mostly treated at the same way, with referment to communal, standard, definition - e.g. cradle-to-gate -, while the economic analysis usually follows similar methods even though different metrics may be involved. Similar considerations hold for profitability analysis as well.

Such a synchronicity existence of converging and diverging points between TEA and LCCA leaves space, and gives reason, to the opportunity to enhance their simultaneous adoption by investigating a methodical integrative framework.

\subsection{Thoughts for an integrative approach: reasons and possible pathways}

Many times, the distinctive elements of the LCCA are adopted by analysts in their techno-economic assessments. However, in most cases, the LCCA is denatured, and its elements are reduced to a discounting process which originates net present value metrics. As a consequence, important features, such as the identification of alternatives or the inclusion of inflationary costs are usually left out of the study. This inadequacy originates from lack of clear standards for both sides, as well as the total absence of any systematic procedure to implement LCCA into TEA. For this reason, if the aim is to integrate TEA and LCCA for an all-inclusive analysis, then a methodical process needs to be developed. Only in this way, the peculiarities of both evaluation methods may be exploited and unified in a more detailed and reliable examination. In order to select the most cost-efficient solution, TEA is already arranged to incorporate investment and performance assessment (Kantor et al., 2010); 
INSIGHTS INTO REGIONAL DEVELOPMENT

ISSN 2669-0195 (online) http://jssidoi.org/jesi/

2021 Volume 3 Number 2 (June)

http://doi.org/10.9770/IRD.2021.3.2(2)

however, this cannot be at the expenses of the completeness of the analyses. This conclusive section by no means wants to give an absolute procedure for integrating the two methods under analysis, but just some insights on a potential approach.

In general, while TEA can be mainly used to identify potential hotspots and technical weaknesses, LCCA may furnish a detailed examination of the economic conditions. In such a way, the relationships between economic and technical performances may result clearer than it is the case of individual adoption of these tools. Also, as already mentioned, LCCA can be implemented to extend the perspective of a TEA. Finally, LCCA may represent for TEA a way to include different viewpoints of some distinctive elements in the analysis, such as uncertainty and time dependency, or systematically address profitability with a specific tool.

First of all, until the technology is validated in a relevant environment (around TRL 5), it is not reasonable to supplement the techno-economic analysis with a LCCA. In the early phases of development, actually, the quality and quantity of data is subject to relevant variability and uncertainty. As proposed by Buchner et al. (2018), until the project is in its mid-phase, qualitative considerations should prevail. It follows that only from an advanced phase more accurate quantitative measures, such as the one adopted through the LCCA ought to enter the analysis. Moreover, as pointed out in the TEA Guidelines for CO2 Utilization (Zimmerman et al., 2018), LCCA may result helpful when extending the boundaries of the analysis. In light of this, however, the practice shows a difficulty to properly assess all costs occurring throughout the entire lifecycle of project, especially when these are far distant in time or do not have the characteristics for a direct economic evaluation.

Much more interesting are the considerations about inflation, time and uncertainty. A through consideration of these elements would provide significant improvements in term of both interpretability and completeness when integrating TEA with LCCA. Recalling what previously, inflation is usually treated through scenario analysis in TEA in order to identify possible influences of price volatility on the project's feasibility, especially on the edge of capital expenditure. However, when LCCA practices are implemented inflation enters the actualisation process and escalate the current expenses (Woodward, 1997). In this way, costs are weighted for inflation and more accurate considerations may arise. Finally, LCCA may introduce in the evaluation more details to understand how inputs and outputs interact to each other. Hence, one of the main features of TEA may be enhanced, as well as the overall uncertainty level reduced. Throughout a cost-oriented sensitivity analysis and break-even analysis, it is possible to highpoint which costs mostly influence the economic viability of the project, usually the NPV. Differently from TEA, which also include technical variables but may lack of some economic considerations, under LCCA uncertainty is deeply investigated in its economic dimension. It follows that, in an integrative approach, other than understanding which technical and economic factors generally affect the performances of the project, the financial feasibility is deeply investigated. This process may also open to the possibility of further examine which technological factors influence the driving costs of feasibility in order to guide even further improvements.

Summarising, techno-economic and life cycle-costing analyses should be kept separate until the project's development reach certain level of development. Then, once more quantitative data are available, LCCA may join TEA supporting the enlargement of boundaries and the inclusion of more explicative variables in the explanation of the economic feasibility of the project. In mid-development phases, LCCA may represent an adequate solution to investigate alternatives of design and NPV. Furthermore, as we mentioned earlier, new aspects of uncertainty may be recognised thanks to the wider range of variables considered. Finally, the LCCA may be enriched itself by TEA, since costs may be also associated to their technical drivers. 
INSIGHTS INTO REGIONAL DEVELOPMENT

ISSN 2669-0195 (online) http://jssidoi.org/jesi/

2021 Volume 3 Number 2 (June)

http://doi.org/10.9770/IRD.2021.3.2(2)

\section{Conclusions and recommendations}

It is undoubted that the techno-economic assessment (TEA) and the life-cycle costing analysis (LCCA) offer valuable insights when evaluating the economic feasibility of technological projects, by also allowing the identification of sensible parameters and connections between inputs and outputs. However, present methodological approaches and standards lack of clear and harmonised frameworks for their implementation. Furthermore, often their structural elements overlap, causing partial examinations and potentially biasing the results and the recommendations.

The purpose of this study was to contribute to a critical and comprehensive explanation of the two appraisal methods with a first consistent attempt to reveal their possible integrability. Overall, we tried to give to practitioners and academia new elements to appraise present literature and structuring new studies. From this, two main contributions resulted from the research:

- The identification and analysis of distinctive elements in the techno-economic and life-cycle costing evaluation procedures; and

- The proactive position towards a potential integrative framework.

The first originated from a deep analysis of different schemes and methodological concepts proposed by literature. It occurred that under a methodological point of view, the methods involve similar procedural steps, such as: boundaries set, cost evaluation, uncertainty and profitability analysis. However, the way they approach these same components may vary in the procedures and details. On the other hand, distinguishing points have been detected in the way they approach time and inflationary effects, technological elements and references for comparisons. While TEA may deeply rely on the level of technological development to define its structure and usually project the future by usually relying on the use of scenario analysis, LCCA does not consider technology and generally brings future to a current meaning with the actualisation of cash flows. To note that also TEA may contemplate net present values to assess the economic feasibility, even though this should happen only in mid-phases of development. Furthermore, LCCA guides the decisions relying on a comparison with alternatives, while TEA identifies benchmarks and weights results on the basis of technical considerations.

However, due to the poor theoretical discussion and wide heterogeneity affecting guidelines and standards, while in theory the methods are differentiable, in practice the distinctive elements of the one and the other may be overlapped. Most of the times this happens with TEA that, trying to broaden its perspective and perfectionate its economic considerations, includes in the analysis features of the LCCA, but without a complete and coherent implementation. From this, the second contribution of this work. It resulted that a positive integration is desirable and may enhance the results of techno-economic analyses, allowing to include more explicative metrics and a larger set of boundaries. In general, a complete and coherent integration may strengthen the connection between the economic and technical aspects of technological advancement, keeping the consistency with the theoretical foundations of the methods. To stress out the fact that, by including only partial elements of one or the other method, may bring to a loss of informative data and define wrong, or less-efficient, pathways of development.

To conclude, the main limitations of this research mainly derive from the strong heterogeneity affecting both practice and theoretical discussion, which make it difficult to state comprehensively the nature of TEA and LCCA. Furthermore, the impossibility to test our propositional concepts of integrability leave the overall discussion on a theoretical approach, which still needs to be proven in actual fact. Still, the hope is that this study 
INSIGHTS INTO REGIONAL DEVELOPMENT

ISSN 2669-0195 (online) http://jssidoi.org/jesi/

2021 Volume 3 Number 2 (June)

http://doi.org/10.9770/IRD.2021.3.2(2)

will contribute to the development of clearer set of rules which would provide higher level of comparability among studies, as well as a more reliable utilization of TEA and LCCA. Through this research we wanted to highlight a problem which, at present time, is not properly discussed but that may significantly influence the reliability of the evaluations based on TEA and LCCA. While acknowledging the preliminary nature of this work, still it provides an innovative approach to investigate the TEA and LCCA, both as individual entities and integrable tools. Also, we are optimist that the initial proposition about an integrative method may act as a starting point for a future, and deeper investigations of the subject.

\section{References}

Asiedu, Y., \& Gu, P. (1998). Product life cycle cost analysis: State of the art review. International Journal of Production Research,36(4), 883-908. https://doi.org/10.1080/002075498193444

Buchner, G. A., Zimmermann, A. W., Hohgräve, A. E., \& Schomäcker, R. (2018). Techno-economic Assessment Framework for the Chemical Industry - Based on Technology Readiness Levels. Industrial \& Engineering Chemistry Research,57(25), 8502-8517. https://doi.org/10.1021/acs.iecr.8b01248

BS 5760-23: 1997 Reliability if systems, equipment and components. Guide to life cycle costing.

Christensen, P., \& Dysert, L. R. (2005). Cost estimate classification system - as applied in engineering, procurement, and constructionfor the process industries.

Coker, A. K. (2007). Cost Estimation And Economic Evaluation. In Ludwig's Applied Process Design for Chemical and Petrochemical Plants (pp. 69-102). Gulf Professional Publishing. https://doi.org/10.1016/b978-075067766-0/50009-9

Cole, R. J., \& Sterner, E. (2000). Reconciling theory and practice of life-cycle costing. Building Research \& Information, 28(5-6), 368375. https://doi.org/10.1080/096132100418519

Diependaele, M. (2018). A guide on the basic principles of Life-Cycle Cost Analysis (LCCA) of pavements. https://www.eupave.eu/wpcontent/uploads/EUPAVE-Guide-on-LCCA-2018.pdf

Directive 2014/24/EU of the European Parliament and of the Council of 26 February 2014 on public procurement and repealing Directive 2004/18/EX Text wit EEA relevance

Directive 2014/25/EU of the European Parliament and of the Council of 26 February 2014 on procurement by entitie operating in the water, energy, transport and postal services sectors and repealing Directive 2004/17/EC Text with EEA relevance

El Haram, M. A., Marenjak, S., \& Horner, M. W. (2002). Development of a generic framework for collecting whole life cost data for the building industry. Journal of Quality in Maintenance Engineering, 8(2), 144-151. https://doi.org/10.1108/13552510210430017

Ellis, B. (2007). Life Cycle Cost. The Jethro Project.

Fabrycky, W., \& Blanchard, B. (1991). Life Cycle Cost and Economic Analysis.

Fisher, G. H. (1970). Cost Considerations in Systems Analysis. RAND Corporation.

Fuller, S. K., \& Petersen, S. R. (1996). Life-cycle costing manual for the Federal Energy Management Program. 1995 edition. Handbook. https://www.nist.gov/publications/life-cycle-costing-manual-fe deral-energy-management-program-nist-handbook-135-1995

Haaker, M. P. R., \& Verheijen, P. J. T. (2004). Local and Global Sensitivity Analysis for a Reactor Design with Parameter Uncertainty. Chemical Engineering Research and Design, 82(5), 591-598. https://doi.org/https://doi. org/10.1205/026387604323142630

Helton, J. C., Johnson, J. D., Sallaberry, C. J., \& Storlie, C. B. (2006). Survey of sampling-based methods for uncertainty and sensitivity analysis. Reliability Engineering and System Safety. https://doi.org/10.1016/j.ress.2005.11.017

Hunkeler, D., Lichtenvort, K., \& Rebitzer, G. (2008). Environmental Life Cycle Costing. CRC Press. https://doi.org/10.1201/9781420054736

ISO 144044 (2006). European Committee for Standardisation, Brussels. Environmental management - Life cycle assessment Requirements and guidelines.

ISO 15663-1 (2000). European Committee for Standardisation, Brussels. Petroleum and natural gas industries - Life cycle costing - Part 1: Methodology.

ISO 15686-5 (2017). European Committee for Standardisation, Brussels. Buildings and constructed assets - Service life planning - Part 5: Life-cycle costing.

Jensen, A., J, E., Christiansen, K., L, H., BT, M., Schmidt, A., \& F, van. (1998). Life cycle assessment (LCA) - a guide to approaches, experiences and information sources.

Kantor, M., Wajda, K., Lannoo, B., Casier, K., Verbrugge, S., Pickavet, M., Wosinska, L., Chen, J., \& Mitcsenkov, A. (2010). General framework for techno-economic analysis of next generation access networks. 2010 12th International Conference on Transparent Optical Networks, 1-4. https://doi.org/10.1109/ICTON.2010.5549342

Kuppens, T., Van Dael, M., Vanreppelen, K., Thewys, T., Yperman, J., Carleer, R., Schreurs, S., \& Van Passel, S. (2015). Technoeconomic assessment of fast pyrolysis for the valorization of short rotation coppice cultivated for phytoextraction. Journal of Cleaner Production, 88, 336-344. https://doi. org/10.1016/j.jc lepro.2014.07.023

Langdon, D. (2007). Life Cycle Costing (LCC) as a contribution to sustainable construction: a common methodology. May, 60. 


\section{INSIGHTS INTO REGIONAL DEVELOPMENT}

ISSN 2669-0195 (online) http://jssidoi.org/jesi/

2021 Volume 3 Number 2 (June)

http://doi.org/10.9770/IRD.2021.3.2(2)

http://scholar.google.com/scholar?hl=en\&btnG=Search\&q=intitle $:$ ife +cycle+costing $+(+\mathrm{LCC}+)+$ as $+\mathrm{a}+$ contribution+to+sustainable + construction+:+a+common+methodology $\# 0 \% 5 \mathrm{Cnhttp} / /$ scholar.google.com/scholar?hl=en\&btnG=Search\&q=intitle $:$ Life $+\mathrm{Cycle}+\mathrm{C}$ osting $+(+\mathrm{LCC}+)+\mathrm{as}+$

Mankins, J. C. (2009). Technology readiness assessments: A retrospective. Acta Astronautica, 65(9-10), 1216-1223. https://doi.org/10.1016/j.actaastro.2009.03.058

Michailos, S., Sanderson, P., Villa Zaragoza, A., McCord, S., Armstrong, K., Styring, P., Mason, F., Stokes, G., Williams, E., Zimmermann, A., Wunderlich, J., Buchner, G., Schomäcker, R., Müller, L., Bardow, A., Bardow, A., Marxen, A., \& Naims, H. (2018). Methanol Worked Examples for the TEA and LCA Guidelines for CO2 Utilization. https://doi.org/10.3998/2027.42/145723

Mytilinou, V., Lozano-Minguez, E., \& Kolios, A. (2018). A framework for the selection of optimum offshore wind farm locations for deployment. Energies, 11(7). https://doi.org/10.3390/en11071855

Rajendran, K., \& Murthy, G. S. (2019). Techno-economic and life cycle assessments of anaerobic digestion - A review. Biocatalysis and Agricultural Biotechnology, 20. https://doi.org/10.1016/j.bcab.2019.101207

Rajesh Banu, J., Preethi, Kavitha, S., Gunasekaran, M., \& Kumar, G. (2020). Microalgae based biorefinery promoting circular bioeconomy-techno economic and life-cycle analysis. In Bioresource Technology (Vol. 302, p. 122822). Elsevier Ltd. https://doi.org/10.1016/j.biortech.2020.122822

Reap, J., Roman, F., Duncan, S., \& Bras, B. (2008). A survey of unresolved problems in life cycle assessment. The International Journal of Life Cycle Assessment, 13(4), 290. https://doi.org/10.1007/s 11367-008-0008-x

Saltelli, A., Annoni, P., Azzini, I., Campolongo, F., Ratto, M., \& Tarantola, S. (2010). Variance based sensitivity analysis of model output. Design and estimator for the total sensitivity index. Computer Physics Communications, 181(2), 259-270. https://doi.org/10.1016/J.CPC.2009.09.018

Shafiee, M., Brennan, F., \& Espinosa, I. (2015). Whole Life-Cycle Costing of Large-Scale Offshore Wind Farms.

Sherif, Y. S., \& Kolarik, W. J. (1981). Life cycle costing: Concept and practice. Omega, 9(3), 287-296. https://doi.org/https://doi.org/10.1016/0305-0483(81)90035-9

Tang, Z. C., Zhenzhou, L., Zhiwen, L., \& Ningcong, X. (2015). Uncertainty analysis and global sensitivity analysis of techno-economic assessments for biodiesel production. Bioresource Technology, 175, 502-508. https://doi.org/10.1016/j.biortech.2014.10.162

Torabi, F., \& Ahmadi, P. (2020). Techno-economic assessment of battery systems. In F. Torabi \& P. Ahmadi (Eds.), Simulation of Battery Systems (pp. 311-352). Academic Press. https://doi.org/https://doi.org/10.1016/B978-0-12-816212-5.00013-1

Van Dael, M., Kuppens, T., Lizin, S., \& Van Passel, S. (2015). Techno-economic Assessment Methodology for Ultrasonic Production of Biofuels. In Biofuels and Biorefineries (Vol. 4, pp. 317-345). https://doi.org/10.1007/978-94-017-9624-8_12

Van Dael, M., Van Passel, S., Pelkmans, L., Guisson, R., Reumermann, P., Luzardo, N. M., Witters, N., \& Broeze, J. (2013). A technoeconomic evaluation of a biomass energy conversion park. Applied Energy, 104, 611-622. https://doi.org/10.1016/J.APENERGY.2012.11.071

Woodward, D. G. (1997). Life cycle costing-theory, information acquisition and application. In Internattonal Journal of Project Management (Vol. 15, Issue 6).

Zayed, M. E., Zhao, J., Li, W., Elsheikh, A. H., Zhao, Z., Khalil, A., \& Li, H. (2020). Performance prediction and techno-economic analysis of solar dish/stirling system for electricity generation. Applied Thermal Engineering, 164. https://doi.org/10.1016/j.applthermaleng.2019.114427

Zimmerman, A., Wunderlich, J., Buchner, G., Müller, L., Armstrong, K., Michailos, S., Marxen, A., Naims, H., Mason, F., Stoke s, G., \& Williams, E. (2018). Techno-Economic Assessment \&amp; Life-Cycle Assessment Guidelines for CO2 Utilization. https://doi.org/10.3998/2027.42/145436

Zimmermann, A., Schomäcker, R., Gençer, E., O’Sullivan, F., Armstrong, K., Styring, P., \& Michailos, S. (2019). Global CO2 Initiative Complete Oxymethylene Ethers Study 2018. https://doi.org/10.3998/2027.42/147468

Zizlavsky, O. (2014). Net Present Value Approach: Method for Economic Assessment of Innovation Projects. Procedia - Social and Behavioral Sciences, 156. https://doi.org/10.1016/j.sbs pro.2014.11.230

\section{Acknowledgements}

This research was supported by the University of Ferrara and the TECNALIA Research and Innovation Center, Derio (Bizkaia), Spain. 
INSIGHTS INTO REGIONAL DEVELOPMENT

ISSN 2669-0195 (online) http://jssidoi.org/jesi/

2021 Volume 3 Number 2 (June)

http://doi.org/10.9770/IRD.2021.3.2(2)

Lorenzo GIACOMELLA is going to take its Master's Degree in Economics, Management and Policies for Global Challenges, curriculum Green Economy and Sustainability, from the University of Ferrara and holds a Bachelor' s Degree in International Economy and International Markets from the University of Trieste. His current interests range in the fields of Sustainability and theoretical economics.

ORCID ID: https://orcid.org/0000-0001-8537-7269

Copyright (C) 2021 by author(s) and VsI Entrepreneurship and Sustainability Center

This work is licensed under the Creative Commons Attribution International License (CC BY).

http://creativecommons.org/licenses/by/4.0/

c) (7) Open Access 